\title{
NEGÓCIOS ÉTNICOS E TECNOLÓGICOS DE BRASILEIROS NA ESTÔNIA: UMA COMUNIDADE IMIGRANTE EM FORMAÇÃO
}

\author{
Ethnic and technological business of Brazilians in Estonia: \\ an immigrant community in formation
}

\author{
Roberto Pessoa de Queiroz Falcão* \\ Eduardo Picanço Cruz ** \\ Ricardo Ferraz Raats ${ }^{* * *}$
}

\begin{abstract}
Resumo. Uma recente imigração de brasileiros para Estônia é revelada no presente artigo, evidenciando trajetórias dos imigrantes e o surgimento de negócios étnicos e tecnológicos. O país situa-se no seio do Mar Báltico e promove a imigração qualificada, focada na economia digital. Foi aplicado um questionário tipo survey a 65 respondentes brasileiros que vivem na Estônia, sendo complementado por oito entrevistas em profundidade com empreendedores brasileiros e artistas que se empresariam no país. Os pesquisadores apresentam as características dessa comunidade em formação e possíveis caminhos para futuros imigrantes, evidenciando aspectos dos negócios étnicos e interações dos brasileiros com a cultura estoniana, trajetórias migratórias, dificuldades enfrentadas e oportunidades levantadas por esses imigrantes.
\end{abstract}

Palavras-chave: Estônia; imigração brasileira; TI; empreendedorismo de imigrantes.

\begin{abstract}
A recent immigration of Brazilians to Estonia is evidenced in this paper, presenting the trajectories of immigrants and the emergence of ethnic and technological businesses. The country is located in the heart of the Baltic Sea and promotes qualified immigration, focused on the digital economy. A survey questionnaire was applied to 65 Brazilian respondents living in Estonia, complemented by eight in-depth interviews with Brazilian entrepreneurs and artists who work in the country. Researchers present the characteristics of an emerging immigrant community and possible paths for future immigrants, highlighting aspects of ethnic businesses and interactions between Brazilians and the Estonian culture, their migratory trajectories, difficulties faced and opportunities raised by these immigrants.
\end{abstract}

Keywords: Estonia; Brazilian immigration; IT; immigrant entrepreneurship.

Professor da Universidade Federal Fluminense. Niterói, RJ, Brasil. E-mail: robertopqfalcao@gmail. com. Orcid: https://orcid.org/0000-0002-8125-0938.

** Professor da Universidade Federal Fluminense. Niterói, RJ, Brasil. E-mail: epicanco@id.uff.br. Orcid: https://orcid.org/0000-0003-4484-3256.

${ }^{* * *}$ Doutorando na Tallinn University of Technology. Tallinn, Estonia. E-mail: ricardo.ferraz@taltech. ee. Orcid: https://orcid.org/0000-0001-6151-7116. 


\section{Introdução}

Desde a última metade do século XIX o Brasil recebeu milhares de imigrantes de todo o mundo (Amaral, Costa, Allgayer, 2017, p. 258). O primeiro grupo de estonianos chegou no início do século XX e pelo menos outros 282 estonianos foram para o país em 1908 (Jürisson, 2012, p. 95). Em um sentido inverso, sobretudo com as crises econômicas da década de 1980, o Brasil tem se mostrado como um país de emigração (Castro Lima, Castro, 2018, p. 273), sendo o contingente de brasileiros que deixaram sua terra natal superior a três milhões. Embora o número oficial não esteja atualizado, a imigração irregular também não aparece nos registros do Itamaraty de 2016.

Milhares de brasileiros continuam depositando suas esperanças no exterior. Ayer (2019) aponta para fatores como a desconfiança, a insegurança e o desejo de melhores oportunidades para o futuro dos filhos. Os destinos têm sido os mais diversos, assim como os motivos que atraem esses brasileiros; os (i) esportivos, como no caso de oportunidades para atletas de futebol (Ribeiro, Dimeo, 2009), professores de jiu-jitsu ou capoeira (Rocha et al., 2015), (ii) os estudantis, como no caso de estudantes de inglês ou intercambistas universitários (Maher, Cawley, 2016), a contratação de profissionais qualificados, como no caso dos profissionais de tecnologia da informação (TI) no Canadá (Kaushik, Drolet, 2018), ou por relacionamento, como no caso das mulheres brasileiras que casam com suíços (Schuler, Souza Brito, 2014).

Ao buscarem um futuro melhor, quer seja por meio do emprego ou de um empreendimento, certamente a busca por informações sobre o local de destino é crucial, seja por meio de intermediários, como agências de trabalho ou intercâmbio (Cruz, Falcão, Paula, 2020) ou das redes sociais como Facebook ou Linkedin (Falcão, Cruz, Amaral, 2018). Geralmente, os que desejam imigrar querem saber sobre o grau de dificuldade e burocracia para imigrar, possibilidades de trabalho ou aspectos relativos ao idioma local, pouco se importando em definir um destino específico - parece que o importante seria apenas deixar o país (Margolis, 2013, p. 7). Vale ressaltar que parte considerável desse contingente passa por um processo migratório "errático" ou mesmo irregular, alguns chegam como turistas e outros se mudam para países terceiros.

Nesse sentindo, a Estônia emerge como um desses destinos fora das rotas tradicionais de emigração brasileira, mas que começa a atrair imigrantes mesmo sendo um país frio, de língua difícil e de certa forma, afastado das referências culturais brasileiras na Europa. Situado no nordeste europeu, em uma zona de influência cultural e econômica entre a Rússia e os Países Nórdicos, o país é banhado pelo Mar Báltico e tem como capital Tallinn. Com uma população de apenas 1,3 milhões, o país conta com uma população de cerca de 220 brasileiros - estimativa do cruzamento de diversas fontes de dados, explicitada na seção Metodologia. A maioria dos brasileiros são quase todos profissionais da área de 
tecnologia, que migraram com o objetivo de abrir uma empresa ou integrar a equipe de uma das 615 empresas startups locais (Jakitas, 2019), embora haja também um contingente que exerça outras atividades.

Na literatura acadêmica, há diversos estudos realizados em comunidades imigrantes brasileiras já estabelecidas (por exemplo, Cruz, Falcão, Paula, 2020; Cruz, Falcão, Mancebo, 2019; Margolis, 2013; Rocha et al., 2015; Schuler, Souza Brito, 2014), porém, pesquisar uma comunidade em formação traz relevância para o presente estudo no sentido de (i) evidenciar trajetórias imigrantes específicas dos brasileiros; (ii) entender como se configuram as redes sociais no início de uma comunidade imigrante; (iii) evidenciar ocupações e negócios que emergem numa comunidade nascente. Além disso, Cruz, Falcão e Mancebo (2019, p. 250) destacam a necessidade de serem realizados estudos longitudinais que possibilitem a análise das mudanças nas configurações dos mercados étnicos. Nesse sentido, o presente artigo pode ser traduzido como um marco a ser revisitado, no futuro.

Assim sendo, buscou-se identificar as características da comunidade brasileira na Estônia, no que concerne à sua capacidade financeira, qualificação profissional, motivação para emigrar, dentre outros fatores. Foi aplicado um questionário tipo survey em uma amostra de 65 indivíduos da população brasileira no país. O mesmo foi veiculado em grupos das redes sociais digitais, aliado a uma estratégia qualitativa de coleta de dados por meio de entrevistas em profundidade, funcionando como triangulação e probing, realizadas na capital Tallinn, de setembro de 2018 a março de 2020.

\section{Imigração em um ambiente de grandes diferenças culturais}

Cada vez mais os negócios de imigrantes e a diversidade étnica vem fazendo parte dos recentes debates a respeito da imigração e assimilação de imigrantes nos países receptores (Boudreaux, 2020). De um lado, há países (ou políticos) que defendem medidas mais rígidas de imigração, promovendo a discriminação étnica e gerando efeitos colaterais aos imigrantes, como o caso atual dos EUA e de alguns países europeus (como visto em Almeida et al., 2016; Schlueter, Masso, Davidov, 2018). Já de outro, defende-se o incentivo às políticas migratórias que buscam atrair mão-de-obra qualificada e com boa educação, sendo este o caso do Canadá (Kaushik, Drolet, 2018) e da Austrália (Chand, Tung, 2019), assim como o da Estônia (Mets, 2017).

A discussão faz sentido na medida em que se avolumam determinados movimentos migratórios, causando o fenômeno de diáspora. Segundo Shuval (2000, p. 42), o termo diáspora adquiriu um amplo domínio semântico, abrangendo uma gama de diferentes grupos, tais como refugiados políticos, residentes estrangeiros, trabalhadores convidados, imigrantes, exilados, minorias étnicas e raciais e comunidades no exterior. Em um sentido mais abrangente, é cada vez mais utilizado para definir os indivíduos, que deslocados de seu país de 
origem, sentem, mantêm, inventam ou revivem suas histórias de dispersão, mitos, memórias da pátria e de alienação no país de acolhimento, possuindo o desejo de um eventual retorno, quer seja ambivalente, escatológico ou utópico. O ponto central está em seu apoio contínuo da pátria e uma identidade coletiva definida pelas relações anteriores. O autor ainda atribui aos membros de uma diáspora um senso comunitário afetivo-expressivo, sendo um construto social fundado no sentimento, consciência, memórias, histórias, narrativas, identidades de grupo, sonhos e elementos virtuais e alegóricos.

Especificamente, a imigração e o empreendedorismo de brasileiros são temas estudados há algumas décadas por autores como Margolis (2013) e Cruz, Falcão e Barreto (2017), os quais evidenciaram as várias estratégias empresariais e empreendedoras, que enfocam tanto os clientes locais quanto os próprios membros das comunidades étnicas. A diáspora brasileira vem ganhando ritmo desde a década de 1980 (Margolis, 2013, p. 7), alimentada por um cenário de longos desequilíbrios econômico-financeiros no país. Cruz, Falcão e Barreto (2017) mostraram que ondas migratórias com diferentes perfis sociais resultaram em comunidades ecléticas, sem um padrão pelo qual o imigrante brasileiro pudesse ser universalmente identificado. $\mathrm{O}$ caso do perfil do imigrante brasileiro geralmente consiste em cidadãos da classe média ou classe média alta, os quais, uma vez estabelecidos, abrem oportunidades para compatriotas com características diferentes, incluindo aqueles que não falam o idioma local e, por sua vez, se tornam os 'padrinhos' da imigração. Segundo Amaral, Costa e Allgayer (2017, p. 279), hoje, os brasileiros são uma parcela significativa de emigrantes em todo o mundo, enfrentando situações de desamparo e dificuldades de manutenção de seus direitos, tanto em relação às redes de apoio do Brasil, como às dos países de destino.

Sobre o destino Estônia, pode se encontrar blogs que listam aspectos desmotivantes, como (i) o clima, úmido e frio, (ii) a cultura, de resistência contra as várias invasões alemã, sueca, dinamarquesa e russa, (iii) o idioma difícil, da família fino-úgricas, (iv) e salários menores quando comparados aos da Europa Central, mas com custo de vida equivalente à cidade de São Paulo, e, sobretudo (v) a distância, sendo uma viagem cara e longa (Poli, 2018). No entanto, o país mantém uma política atrativa de imigrantes buscando profissionais qualificados em áreas específicas, especialmente a do setor de TI, voltada para estudantes e profissionais estrangeiros que possam aderir às diversas ações do programa "cidadão digital" (Tammpuu, Masso, 2018, p. 547). Destacam-se pelo menos 80 empresas virtuais estabelecidas por brasileiros no país (E-Resident, 2019). No entanto, em paralelo aos negócios digitais negócios típicos de subsistência e auto-emprego começam a aparecer no seio da comunidade brasileira, como iniciativas de artes, danças e apresentações musicais, salões de beleza, serviços caseiros para brasileiros e culinária típica. 


\section{O conceito de comunidade e de negócios étnicos no contexto atual}

Bauman (2003) em sua obra que discute o conceito de comunidade, desde os pensadores clássicos até o advento da sociedade digital pós-moderna, evidencia as dinâmicas de convivência humanas em tempos de redes sociais e globalização, sendo influenciadas por um pré-conceito acrítico do conceito de comunidade, que segundo o autor, nos remete a uma ideia de uma "coisa boa" (Soczek, 2004, p. 175), ou de um "círculo harmonioso" (Rosenberg, 1977, p. 129) ou mesmo de um agrupamento "distinto, pequeno e autossuficiente" (Redfield, 1989, p. 5). Nesse sentido, segundo Bauman (2003), em algum momento da história firmou-se o conceito positivo de comunidade, talvez oriundo da mitologia grega ou bíblica, uma ideia de paraíso ligada à inocência e ao pertencimento a um grupo sem interesses individualistas (Soczek, 2004, p. 174). Contudo, há uma tensão presente entre a segurança utópica e almejada com a concepção da liberdade imprecisa. Portanto, mesmo ao considerarmos comunidades de imigrantes, pode-se supor uma almejada e resistida segurança coletiva, em prol da liberdade individual (Bauman, 2003). Os dilemas da sociedade presentes no conceito da modernidade líquida de Bauman, se inserem em uma tensão relativa ao conflito entre os produtores e as fontes de sobrevivência, os negócios e o lar. Nesse sentido, há uma ruptura dos laços morais e emocionais, onde as comunidades agem pelo medo que vem "de dentro" das pessoas, não sendo mais necessário um panóptico externo. A dicotomia entre a liberdade e a segurança, como afirma Bauman (2003), é proveniente de consequências oriundas dos contextos pós-modernos, da exploração, da perpetuação e do aprofundamento da estratificação da sociedade em classes econômicas, com a formação de guetos, ou seja, uma exacerbação da negação do conceito de comunidade. Portanto, segundo Bauman (2003), a ideia de comunidade é destruída concomitantemente com a necessidade de pertencimento, demandada pela sociedade. Ademais, os mais abastados da sociedade, que não se importam com a ideia de comunidade, preferem o isolamento, dado que não vislumbram benefícios de permanecerem no seio de suas comunidades (Bauman, 2003, p. 814). Os imigrantes, quando em condições econômicas precárias, agrupam-se em comunidades ou enclaves étnicos (Portes, Zhou, 1992, p. 499). Já quando possuem condição econômica diferenciada, buscam muitas vezes isolar-se de suas comunidades e são criadores de empresas inovadoras (Wadhwa et al., 2007).

Por outro lado, a definição de negócios étnicos está intrinsecamente ligada aos fluxos migratórios e às mesmas comunidades étnicas ou enclaves, tratando-se de uma forma de empreendedorismo motivado inicialmente pela "necessidade" e em geral autônomo ou de microempresas (Waldinger, Ward, Aldrich, 1985, p. 587). Com o passar do tempo, depois de estabelecidos, esses passam a mudar de condição, criando as chamadas "empresas étnicas". Os autores seminais do campo da sociologia que estudaram esses conceitos in loco foram Light (1972), 
Waldinger, Ward e Aldrich (1985), além de Chaganti e Greene (2002), assim como estudos mais recentes a exemplo do de Jones e Ram (2007) que revisitam o conceito de negócios étnicos.

Segundo Kloosterman e Rath (2001), diferentes perspectivas teóricas tentam abordar como se enquadram as interações entre empreendedores e ambiente no caso de empreendedores étnicos e imigrantes. Em primeiro lugar, a perspectiva interativa explica o início de negócios de imigrantes para atender às demandas étnicas de suas comunidades (Gold, Light, 2000). Em segundo lugar, a perspectiva culturalista enfoca os aspectos culturais de certos países de origem (Raijman, Tienda, 2003).

Fatores culturais foram considerados por muitos como causas que explicariam a super-representação de auto-emprego (ou trabalho autônomo) por parte de certos grupos étnicos, como os sul-asiáticos na Grã-Bretanha (Barrett, Jones, Mcevoy, 1996), atribuindo fatores não econômicos à intenção de empreender, sendo intrinsecamente ligado às redes sociais. Os trabalhos pioneiros de Ivan Light (1972), de Portes e Bach (1985) e de Portes e Zhou (1992), a respeito do enclave étnico, ilustram a importância dos nichos étnicos baseados em redes sociais estreitas, ou comunidades étnicas fechadas, onde ocorrem transação de bens e serviços consumidos por clientes co-étnicos. As perspectivas econômicas também são outra corrente que aponta para a diferença entre o valor presente esperado dos rendimentos do trabalho autônomo em comparação com o valor presente esperado dos salários por ser um funcionário de uma empresa local, embora isso seja também influenciado pela experiência gerencial ou tradição de negócios de certos grupos étnicos, o que também sofre influência cultural (Gollin, 2008). Terceiro, a perspectiva ecológica aponta para a exploração de certos nichos de mercado que não são atendidos pelos habitantes locais (Aldrich, Reiss, 1976). Quarto, a perspectiva de incorporação social engloba contextos sociais e regulatórios como fatores explicativos para o trabalho autônomo de imigrantes (Guarnizo, Portes, Haller, 2003). Ademais, em geral os imigrantes brasileiros na atualidade inserem-se em dois contextos de trabalho: (i) trabalhadores do conhecimento altamente qualificados, geralmente relacionados ao setor de TI, e (ii) atividades "servis" de baixa qualificação (Scott, 2012), quer como empreendedores ou empregados, atividades essas geralmente relacionadas ao trabalho autônomo, restaurantes e padarias, salões de beleza, etc. (Cruz, Falcão, Barreto, 2017; Cruz, Falcão, Mancebo, 2019).

Por fim, cabe destacar o trabalho de Cruz et al. (2017) acerca das trajetórias dos empresários étnicos, organizando a figura a seguir: 


\section{Figura 1 - Trajetórias de empreendedores imigrantes}

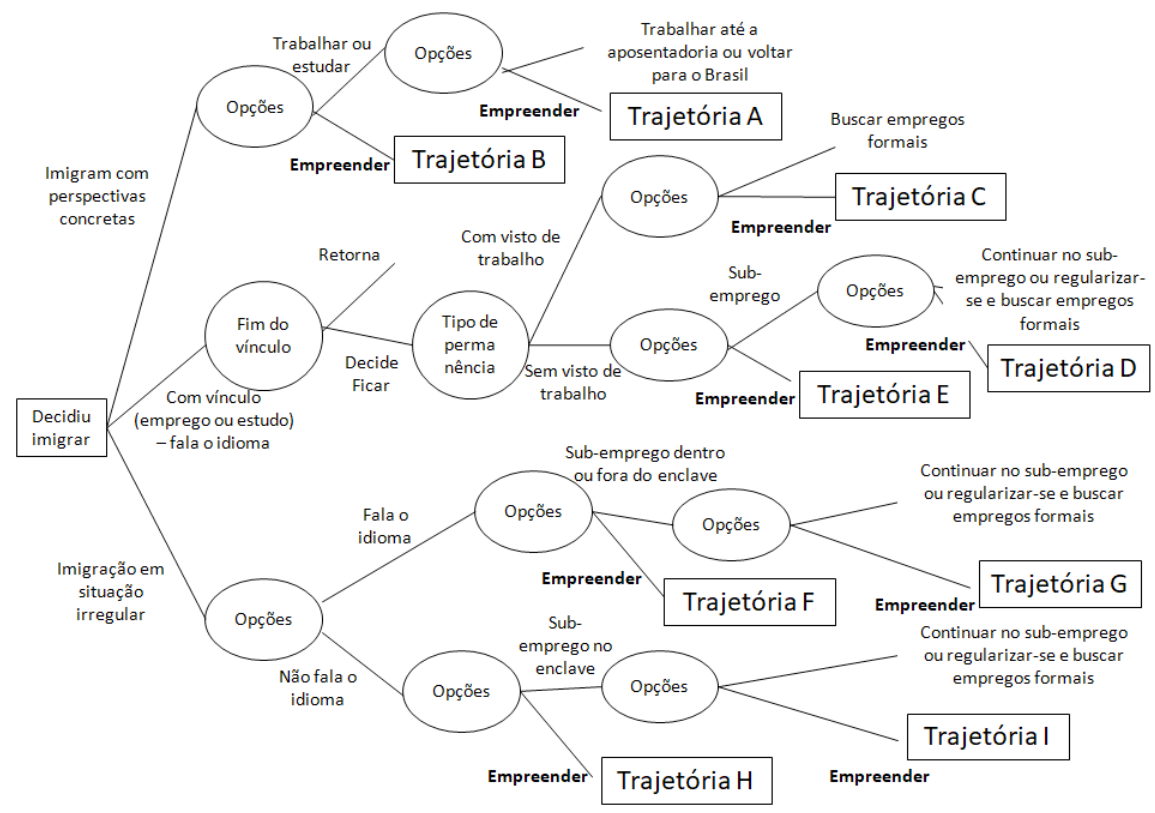

Fonte: Cruz et al. (2017).

\section{Estônia, a república digital do Mar Báltico}

A Estônia tem fomentado uma cultural digital. Dado à demanda por habilidades e conhecimentos em TI, há uma escassez de programadores e outros trabalhadores especializados (Ibrus, 2017). A sustentabilidade do setor depende de métodos educacionais atualizados e da melhoria no currículo das escolas para atender às necessidades das empresas de TI (Pedaste et al., 2017). Na União Europeia, o número de graduados vem diminuindo desde 2006, e as previsões mostram que em 2020 poderá haver escassez de profissionais de TI maior do que 1,5 milhão de especialistas (Hüsing et al., 2013). Uma possibilidade complementar às políticas educacionais é a do fomento à imigração qualificada de profissionais de tecnologia e o estabelecimento de startups que possam vir a se tornar born globals (Mets, 2016).

Mercados globais são particularmente importantes para pequenos países emergentes quando empenhados em manter equilibrados seus sistemas nacionais de inovação, uma economia baseada no conhecimento e no dinamismo da sociedade em geral (Petraite, Dlugoborskyte, 2017). Além disso, com a necessidade de as pequenas e médias empresas se estabelecerem internacional ou até globalmente, se dá a criação de novos empregos ligados à inovação tecnológica, induzindo mais empregos em outros setores e gerando um efeito multiplicador até cinco vezes maior 
que de outros setores (Moretti, 2012). No entanto, para a criação bem-sucedida de ecossistemas empreendedores high-tech, há a necessidade de uma configuração de componentes que incluam atores tangíveis e intangíveis (Mets, 2017), como: mercados nacionais e estrangeiros acessíveis, capital humano incluindo talentos gerenciais e técnicos com experiência empresarial, financiamento, sistemas de suporte, estrutura regulatória, infraestrutura de telecomunicações, internet e transporte, educação, treinamento, parques tecnológicos e incubadoras.

A Estônia, que ingressou na União Europeia em 2004, tem promovido a aglomeração de empresas de e-services em seu desenvolvimento regional (Kattel, Mergel, 2018), pretendendo alcançar um patamar semelhante ao da economia finlandesa, embora tenha aproximadamente 30.000 empregos de alta qualificação parcialmente atendidos (Mets, 2017). Para esse fim, sendo um país pequeno, o investimento em tecnologia e born globals baseadas no conhecimento é uma das melhores soluções para se alcançar mercados em todo o mundo (Mets, 2016). O país também já implementou o conceito de e-gov como plataforma (GaaP) para compartilhar dados e diversos serviços digitais centralizados. Dentro dessa política, é produzida uma imagem única da cidadania digital, ganhando uma reputação global (Margetts, Naumann, 2017).

Pajumets (2019) explica que a recente adoção do Startup Visa deve ser vista como o principal distanciamento das abordagens tradicionais à imigração na Estônia. Anteriormente, os laços econômicos, culturais, históricos e familiares existentes eram a principal base de entrada e permanência legal. Porém, com essa política, o potencial de contribuir para a economia e a sociedade torna-se suficiente para permitir a entrada no país. Na sociedade pós-moderna, ocorre também o fenômeno do nomadismo digital ou nómada digital, que são os indivíduos que aproveitam a tecnologia para realizar tarefas de seu trabalho de forma remota e, pelo fato de não depender de uma base fixa para trabalhar, conduz seu estilo de vida de uma maneira nômade (Schlagwein, 2018). Portanto, também a Estônia se insere nesse novo conceito de comunidades digitais, onde está presente a personalização de conhecimento (Jarrahi et al., 2019), o trabalho digital e o fenômeno do nomadismo de alta tecnologia (Wang et al., 2018) e a profissionalização e corporatização desse mesmo nomadismo digital (Aroles, Granter, Vaujany, 2020).

\section{Metodologia}

De acordo com dados oficiais de 2016 do Ministério das Relações Exteriores - MRE, em sua última contagem, havia em torno de 50 brasileiros morando na Estônia. Dado que não existe uma métrica para estimar o número total de imigrantes, bem como para atualizar os dados para a corrente data, ao se considerar o número de fundadores de empresas virtuais, em uma primeira estimativa chega-se a 250 pessoas, equivalente ao número de participantes de um grupo do Facebook mediado pelos integrantes do conselho de brasileiros (Brasileiros na Estônia, 2019). 
Ao se contrastar esse dado com a estimativa mais recente feita pelo consulado brasileiro local, chega-se, segundo informações obtidas por um dos pesquisadores, a 150 brasileiros legais e outros 70 dentre pessoas com dupla cidadania, ou não registradas nas representações diplomáticas (Embaixada do Brasil em Tallin, 2019), totalizando 220 indivíduos. A amostragem foi feita por conveniência, sendo não probabilística, e definida por acessibilidade.

\subsection{Estratégias de Coleta de Dados}

Baseando-se no trabalho de Baltar e Icart (2013), vale-se da veiculação de questionários do tipo survey, em grupos das redes sociais Facebook e Whatsapp, para gerar dados primários sobre a população brasileira local, no período entre setembro de 2018 e agosto de 2019. Foram usados o grupo aberto "Brasileiros na Estônia", e o grupo fechado "Brasileiros que Moram na Estônia". Por meio dessa estratégia foi alcançado um total de 65 respostas, o que representa mais do que o número de votantes registrados na Embaixada, segundo dados informados diretamente ao pesquisador pelo Itamaraty. Ao fim dos questionários de survey, foram propostas algumas perguntas abertas ("probing").

O questionário continha 26 perguntas, sendo nove fechadas e 17 abertas. As perguntas foram orientadas por estudos semelhantes com brasileiros no Reino Unido (Evans et al., 2007) e na Austrália (Cruz et al., 2016) e objetivaram identificar: (i) o perfil sócio econômico dos respondentes; (ii) as razoes para a saída do Brasil e escolha da Estônia; (iii) como está vivendo; e (v) as dificuldades enfrentadas na chegada e atualmente.

Em termos de ética de pesquisa, o projeto seguiu as normas do comitê de ética de ambas as universidades dos pesquisadores, quer seja no tocante à coleta de dados, quanto no que diz respeito à análise. Os questionários buscaram a proteção ao sigilo dos dados dos respondentes e de sua identidade. Foram também informados ao comitê de ética, os critérios de exclusão e inclusão de respondentes e as formas de recrutamento (que se deu pelo contato pessoal, por meio de indicação dos órgãos consulares locais e pela rede de relações do pesquisador que fez o trabalho de campo).

Em uma fase subsequente, foram realizadas também oito entrevistas em profundidade semi-estruturadas, na capital Tallinn, no período compreendido entre setembro de 2018 e março de 2020, sendo convidados 8 dos primeiros imigrantes que se estabeleceram no país desde a primeira década dos anos 2000, por meio da técnica de amostragem "bola de neve" (Atkinson, Flint, 2001), onde um respondente indica outros de sua rede de relacionamento. As entrevistas foram realizadas segundo a conveniência dos entrevistados em seus locais de moradia ou de trabalho, gravadas e posteriormente transcritas integralmente, tendo durado cerca de 1 hora e 10 minutos cada, e gerando um total de 12 horas 33 minutos de gravação e 128 páginas de transcrição. O roteiro de entrevistas possuía quatro 
seções, destinadas a explorar: (i) as experiências migratórias dos participantes; (ii) sua qualificação, emprego e empreendedorismo antes e depois da saída do Brasil; (iii) sua experiência no processo de abertura da empresa no país de destino; e (iv) informações relacionadas ao marketing e a estratégia dos negócios.

\subsection{Estratégias de Análise de Dados}

Os dados da survey foram consolidados através de estatística descritiva, visando-se obter uma fotografia dos dados sócio demográficos e da trajetória migratória dos respondentes.

A análise e categorização das entrevistas foi dividida em fases, seguindo o protocolo de Bardin (2006), sendo a primeira delas relacionada ao processo de organização, composta de quatro sub-etapas: i) uma primeira leitura dos textos transcritos (leitura flutuante) das entrevistas; ii) escolha dos trechos mais significativos das entrevistas; iii) formulação de hipóteses anteriores derivadas das entrevistas; iv) referenciamento de índices e elaboração de indicadores, através do recorte de passagens nos textos analisados. Uma segunda fase consistiu na exploração do material com a definição de categorias, que de fato foram influenciadas pelo roteiro semiestruturado das entrevistas, pois havia questões específicas a serem investigadas no roteiro. Já na terceira fase, onde ocorreu o tratamento dos resultados, inferência e interpretação, uma análise reflexiva e crítica foi realizada nos relatos das entrevistas.

\section{Perfil dos brasileiros na Estônia}

A tabela 1 apresenta um resumo do perfil sócio demográfico da amostra.

Tabela 1 - Perfil sócio demográfico da amostra

\begin{tabular}{l|l|l|l|l|l|l}
\hline \multicolumn{2}{c}{ Idade } & \multicolumn{2}{c}{ Como chegou na Estônia? } & \multicolumn{2}{c}{ Quanto tempo pretende ficar? } \\
\hline Até 20 anos & $1,8 \%$ & Com visto de estudante & $15,8 \%$ & Entre 1 e 5 anos & $22,8 \%$ \\
\hline 21 a 30 anos & $35,1 \%$ & Com visto de trabalho & $24,6 \%$ & Para sempre & $36,8 \%$ \\
\hline 31 a 40 anos & $50,9 \%$ & Com visto de turista & $43,9 \%$ & Menos de 1 ano & $5,3 \%$ \\
\hline 41 a 50 anos & $7,0 \%$ & $\begin{array}{l}\text { Já cidadão ou para } \\
\text { reivindicar cidadania }\end{array}$ & $12,3 \%$ & $\begin{array}{l}\text { Mais de 5 anos - } \\
\text { pretendendo voltar }\end{array}$ & $8,8 \%$ \\
\hline Mais de 51 anos & $5,3 \%$ & Visto permanente & $3,5 \%$ & \multicolumn{2}{c}{ Entre 1 e 5 anos } & $22,8 \%$ \\
\hline \multicolumn{1}{c|}{ Sexo } & & \multicolumn{1}{c|}{ Onde se formou? } & \multicolumn{2}{c}{ Pensa em abrir um negócio? } \\
\hline Masculino & $63,2 \%$ & $\begin{array}{l}\text { Universidade privada do } \\
\text { Brasil }\end{array}$ & $46,8 \%$ & Não & $49,1 \%$ \\
\hline Feminino & $36,8 \%$ & $\begin{array}{l}\text { Universidade pública do } \\
\text { Brasil }\end{array}$ & $46,8 \%$ & Sim & $50,9 \%$ \\
\hline- & - & Em universidade no exterior & $6,4 \%$ & - & - \\
\hline
\end{tabular}




\begin{tabular}{l|l|l|l|l|l}
\multicolumn{2}{c}{ Tempo na Estônia } & \multicolumn{2}{c}{ Formação } & \multicolumn{2}{c}{$\begin{array}{c}\text { q que está fazendo } \\
\text { atualmente? }\end{array}$} \\
\hline Menos de 1 ano & $47,4 \%$ & Graduação & $49,1 \%$ & $\begin{array}{l}\text { Buscando oportunidades } \\
\text { para abrir um negócio }\end{array}$ & $3,5 \%$ \\
\hline Entre 1 e 4,9 anos & $36,8 \%$ & Pós-Graduação - Lato Sensu & $8,8 \%$ & $\begin{array}{l}\text { Buscando oportunidades } \\
\text { para trabalhar }\end{array}$ & $10,5 \%$ \\
\hline Entre 5 e 9,9 & $7,0 \%$ & Mestrado & $19,3 \%$ & É empresário & $5,3 \%$ \\
\hline Mais de 10 anos & $8,8 \%$ & Doutorado & $1,8 \%$ & Só estudando & $8,8 \%$ \\
\hline - & - & Ensino fundamental & $3,5 \%$ & Só Trabalhando & $54,4 \%$ \\
\hline- & - & Ensino médio & $17,5 \%$ & Trabalhando e estudando & $17,5 \%$ \\
\hline
\end{tabular}

Fonte: Desenvolvimento próprio.

A amostra caracterizou-se, sobretudo, por indivíduos de perfil etário mais maduro, estando 50,9\% deles entre 31 e 40 anos, denotando uma faixa economicamente ativa, além de $35,1 \%$ entre 21 e 30 anos, de estudantes ou indivíduos em início de carreira profissional. Já quanto ao gênero dos respondentes, a amostra teve predominância $(63,2 \%)$ masculina. Relativo à sua escolaridade, os respondentes apresentaram perfil semelhante ao de outras localidades (ver, por exemplo, Austrália - Cruz et al., 2016), sendo grande parte dos respondentes portadores de diploma superior ( $79 \%$ da amostra), e uma fatia considerável deles detentores de diploma de pós-graduação (29,9\%), o que sugere que o Brasil está perdendo profissionais qualificados $(46,8 \%$ graduaram-se em universidades públicas) que emigram do país. Relativo ao tempo de permanência, $84,2 \%$ dos respondentes declaram estar na Estônia há menos de cinco anos, o que representa 49 dos 65 respondentes e caracteriza uma comunidade imigrante recémestabelecida na Estônia.

Já a dificuldade com o idioma, apontado por Poli (2018), é evidenciada por $44 \%$ dos respondentes que informaram ter feito cursos de línguas, destacando-se que nem todos declararam estudar apenas a língua estoniana - russo e inglês também foram citados. Dos dados relativos ao tempo de permanência no país, $63,1 \%$ declararam intenção de ficar para sempre ou não têm previsão, o que também mostra nitidamente a perspectiva de saída definitiva do Brasil.

O trabalho em empresas de terceiros é a principal ocupação relatada pelos brasileiros que moram na Estônia, porém, o número de respondentes que informa ser empresário ou que está buscando oportunidades para empreender $(8,8 \%)$ reforça a importância de se pesquisar o empreendedorismo de imigrantes (ou auto-emprego), o que será visto nos resultados das entrevistas. Algumas perguntas abertas, chamadas "probing", foram também propostas aos respondentes englobando perguntas como: "Por que deixou o Brasil?", "Por que a Estônia te atraiu?", "Qual é o seu Propósito na Estônia?". Os respondentes destacaram a busca por melhores oportunidades de emprego, a procura por melhor qualidade de vida, ter segurança para criar os filhos, a instabilidade política e econômica brasileiras. 
Já ao responderem à pergunta "Quais as principais dificuldades enfrentadas ao chegarem ao país?", corroborando com Jakitas (2019), idioma, cultura e clima aparecem dentre as principais respostas. E ao responderem "Quais as principais dificuldades enfrentadas hoje?", o idioma ainda aparece em primeiro lugar, citado $33 \%$ das vezes.

\section{Trajetórias migratórias e empreendedorismo nascente}

Visando ilustrar melhor as trajetórias imigrantes, foram selecionados alguns temas recorrentes nos discursos, seguindo a metodologia anteriormente apresentada. A tabela 2 apresenta uma visão geral dos entrevistados.

Tabela 2 - Dados Sócio demográficos dos entrevistados

\begin{tabular}{|c|c|c|c|c|c|}
\hline \# & $\begin{array}{c}\text { Idade, Gênero, } \\
\text { Cidade }\end{array}$ & Qualificação & $\begin{array}{l}\text { O que fazia } \\
\text { (Brasil) }\end{array}$ & $\begin{array}{c}\text { Ramo de Negócio } \\
\text { (Estônia) }\end{array}$ & $\begin{array}{l}\text { Tempo } \\
\text { (Estônia) }\end{array}$ \\
\hline 1 & $\begin{array}{l}\text { 30/Masculino, } \\
\text { Piracicaba, SP }\end{array}$ & $\begin{array}{l}\text { Superior, } \\
\text { Comunicação social/ } \\
\text { cinema }\end{array}$ & $\begin{array}{l}\text { Empresário de } \\
\text { fabricação de } \\
\text { impressoras-3D }\end{array}$ & $\begin{array}{l}\text { Indústria 4.0/ } \\
\text { Robótica }\end{array}$ & 1 ano \\
\hline 2 & $\begin{array}{l}\text { 64/Masculino, } \\
\text { Porto Alegre, RS }\end{array}$ & $\begin{array}{l}\text { Ensino Médio, curso } \\
\text { treinador, UEFA }\end{array}$ & $\begin{array}{l}\text { Jogador e treinador } \\
\text { de futebol }\end{array}$ & $\begin{array}{l}\text { Jogador e treinador } \\
\text { de futebol }\end{array}$ & 11 anos \\
\hline 3 & $\begin{array}{l}\text { 37/Feminino, } \\
\text { Porto Alegre, RS }\end{array}$ & $\begin{array}{l}\text { Canto, costuro e } \\
\text { desenho. Técnico } \\
\text { em processamento } \\
\text { de dados, locutora e } \\
\text { radialista. }\end{array}$ & $\begin{array}{l}\text { Já cantava, não } \\
\text { profissionalmente }\end{array}$ & $\begin{array}{l}\text { Primeira cantora } \\
\text { brasileira (Bossa } \\
\text { nova) }\end{array}$ & 13 anos \\
\hline 4 & $\begin{array}{l}\text { 40/Masculino, } \\
\text { Belo Horizonte, } \\
\text { MG }\end{array}$ & $\begin{array}{l}\text { Capoeira, formações } \\
\text { em psicologia do } \\
\text { esporte. }\end{array}$ & $\begin{array}{l}\text { Professor de } \\
\text { capoeira }\end{array}$ & $\begin{array}{l}\text { Professor de } \\
\text { capoeira }\end{array}$ & $\begin{array}{l}3 \text { anos na Estônia } \\
\text { (23 na Europa - } \\
\text { Portugal, Bélgica, } \\
\text { Ucrânia) }\end{array}$ \\
\hline 5 & $\begin{array}{l}\text { 28/Masculino, } \\
\text { São Paulo, SP }\end{array}$ & Engenharia elétrica & $\begin{array}{l}\text { Jogador de pôquer } \\
\text { em tempo integral }\end{array}$ & $\begin{array}{l}\text { Atendimento ao } \\
\text { cliente (na Bolt) e } \\
\text { jogador de pôquer } \\
\text { (não tem taxação) }\end{array}$ & 1 ano \\
\hline 6 & $\begin{array}{l}\text { 33/Masculino, } \\
\text { São Paulo, SP }\end{array}$ & $\begin{array}{l}\text { Pós-graduação em } \\
\text { Project, Management }\end{array}$ & $\begin{array}{l}\text { Micro-empresário } \\
\text { (Desenvolvimento } \\
\text { de software) }\end{array}$ & $\begin{array}{l}\text { Ainda não está } \\
\text { trabalhando }\end{array}$ & 1 ano \\
\hline 7 & $\begin{array}{l}\text { 59/Masculino, } \\
\text { Curitiba, PR. }\end{array}$ & $\begin{array}{l}\text { Mestre em direito e } \\
\text { iniciei um doutorado } \\
\text { na universidade de } \\
\text { Buenos Aires }\end{array}$ & $\begin{array}{l}\text { Mestre de karatê } \\
\text { era empresário no } \\
\text { Brasil. Fui advogado } \\
\text { durante } 30 \text { anos } \\
\text { e nos últimos } 7,8 \\
\text { anos empresário de } \\
\text { construção civil }\end{array}$ & $\begin{array}{l}\text { Academias de artes } \\
\text { marciais (karatê e } \\
\text { jiu-jitsu) }\end{array}$ & 1 ano \\
\hline 8 & $\begin{array}{l}\text { 34/Masculino, } \\
\text { Rio de Janeiro, } \\
\text { RJ }\end{array}$ & $\begin{array}{l}\text { Iniciou faculdade } \\
\text { de música, mas não } \\
\text { concluiu }\end{array}$ & $\begin{array}{l}\text { Músico, projetos } \\
\text { culturais, dança, } \\
\text { produção de eventos }\end{array}$ & Faz shows e eventos & 10 anos \\
\hline
\end{tabular}

Fonte: elaboração própria.

Apresentam-se sinteticamente as trajetórias dos entrevistados, classificando-as de acordo com a taxonomia de Cruz et al. (2017). O entrevistado 1 relatou estar 
estressado com seu negócio no Brasil e a mentalidade do consumidor brasileiro. Começaram a perder vendas entre 2015 e 2016, quando os clientes (empresas) estagnaram suas atividades. Cansou-se, comprou a passagem num dia e viajou no outro. Foi para Irlanda treinar o inglês e usou o tempo para trabalhar em um novo negócio. A Estônia o atraiu pela facilidade em empreender: "No Brasil temos esse trauma por causa da burocracia e lá é o contrário" - enquadrado como trajetória E.

O entrevistado 2 era jogador e treinador de futebol na década de 1980. Estava morando na Finlândia (como treinador) e ia para a Estônia no verão, jogar beach soccer. Através dessa atividade recebeu convite para ser treinador nesse país - enquadrado como trajetória $C$.

A entrevistada 3 trabalhava num salão de beleza afro na Tijuca (RJ) e cantava por hobby. Tocava em um bar para muitos estrangeiros onde fez contatos e trabalhos como cantora. Recebeu um convite para ir à Estônia e aceitou pela possibilidade de conhecer um novo país, aprender outro idioma, sair do mesmo lugar. A empresa de entretenimento e shows que a contratou foi vendida. Então, o novo dono sugeriu que ela abrisse uma empresa na Estônia para continuar legalmente - enquadrado como trajetória $\mathrm{E}$.

O entrevistado 4 era empregado no Brasil e chegou na Europa por Portugal, em 2000, para passar férias. Acabou ficando e abriu uma instituição que "vende", ensina a cultura brasileira, não só a capoeira. A Estônia foi um desafio, assim como a Ucrânia e a Bélgica. A matriz fica nesse país por causa das condições oferecidas: fiscais e jurídicos. Lá, conseguiu transformar a capoeira em profissão - enquadrado como trajetória G.

Formado em engenharia elétrica, o entrevistado 5 é jogador de pôquer em tempo integral há mais de 4 anos. Nunca teve carteira de trabalho, mas na Estônia tem uma empresa tipo MEI (Micro Empreendedor Individual) do Brasil para recolher os impostos. Teve uma oportunidade de morar no exterior por conta de um intercâmbio em Dublin. Descobriu a Estônia pelo Linkedln (Rede Social), uma startup oferecia um emprego nesse país - enquadrado como trajetória C.

Microempresário de desenvolvimento de software no Brasil, esse é o perfil do entrevistado 6. Demorou muitos anos para sair do Brasil. Ficou pesquisando, tentando entender como são as empresas e o governo, que fazia "propaganda" para a área de TI. Foi conversar com as outras pessoas sobre essa ideia. Acredita que apesar do governo vender a imagem perfeita do negócio, a Estônia também tem seus problemas - enquadrado como trajetória B.

O entrevistado 7 era empresário da área de construção civil no Brasil, advogado. Tinha a luta apenas como esporte (karatê e jiu-jitsu). A principal motivação foi a decepção com o caminho que a economia tomou nos últimos anos, demorando 2 anos para deixar o país. Passou um ano nos EUA e foi para a Estônia em razão de uma paixão, se casou com uma estoniana. Sentiu necessidade imediata de buscar formas de desenvolvimento, crescimento pessoal 
e econômico-financeiro e surgiram as possibilidades de trabalhar com ramo de esporte - enquadrado como trajetória B.

O último entrevistado sempre foi músico, depois começou a se envolver com outros projetos culturais: dança, produção de eventos etc. Organizava eventos no Brasil. Deixou o país por motivação pessoal. Foi para a Estônia através de um contrato de trabalho do Ministério da Cultura da Estônia. Nunca tinha escutado falar desse país, mas topou - enquadrado como trajetória C.

Apesar de diferentes, verifica-se uma prevalência da trajetória $C$, sendo que 5 dos 8 casos se deram através de um convite de trabalho. A seguir são apresentados trechos dos depoimentos das entrevistas que ilustram algumas questões relevantes dessas trajetórias e relativas à diáspora brasileira na Estônia, a formação das comunidades e ao empreendedorismo étnico, além de uma breve discussão dos achados.

\subsection{A caracterização da diáspora brasileira na Estônia}

No tocante aos elementos da diáspora (Shuval, 2000), as entrevistas em profundidade revelaram que muitos deixaram o Brasil por causas repulsivas (Ayer, 2019).

Eu estava muito estressado com o negócio lá. O consumidor brasileiro tem uma mentalidade, de que você é empregado dele [...]. Acha que você tem que atender ele na hora que ele quer e do jeito que ele quer. [...] Entre 2015 e 2016 [...] as empresas entraram no modo "não vamos gastar" [...] a gente começou a entrar em declínio de vendas, por conta dessa situação política e econômica do Brasil. (entrevistado 1)

O Brasil é um mercado que não dá para trabalhar, para mim não dá, é um mercado que não é lucrativo para mim. (entrevistado 4)

Situação financeira, econômica do Brasil [...] é complicado ter uma boa qualidade de vida sem ser rico dentro do Brasil. [...] no meu ponto de vista no Brasil não existe classe média [...] (entrevistado 5)

A principal motivação foi a decepção com o caminho que a economia tomou nos últimos anos. [...] aqui posso fazer algo melhor para mim e minha família. (entrevistado 7)

O fato de a Estônia ser um país focado em TI (Mets, 2016, p. 102) também foi destacado como fator de atração.

Então, (a Estônia) é um dos lugares que como uma pessoa da área de TI [...] bo(ns) pra estar, né, apesar de não ter... meu trabalho não ser aqui, mas de certa maneira você tá no meio da área de tecnologia e vai criando os contatos [...] você já tá inserido no lugar... [...]. O mundo foi ficando mais conectado e hoje em dia você consegue ser contratado por uma empresa ... (entrevistado 6)

Falcão, Cruz e Amaral (2018, p. 130) destacaram que muitos brasileiros buscam sair do país, mesmo sem um conhecimento aprofundado do destino, fato corroborado pelos depoimentos: 
Eu não conhecia a Estônia antes de sair do Brasil, eu inicialmente fui pra Irlanda, fui pra lá para treinar meu inglês. (entrevistado 1)

Na verdade, acabei vindo para cá em razão de uma paixão, acabei me casando com uma estoniana e depois que eu vim para cá, eu comecei a buscar todas as informações possíveis e imaginárias... (entrevistado 7)

Fui convidado pelo governo da Estônia, [...] eu recebi uma ligação em inglês [...] imediatamente aceitei participar, ouvi mais sobre o projeto, [...] fui descobrindo aos poucos, né. Nunca tinha escutado falar da Estônia antes, então aos poucos eu fiz as minhas pesquisas. (entrevistado 8)

Dado que o conceito de diáspora (Shuval, 2000), de modo mais abrangente, refere-se aos indivíduos que mantêm, inventam ou revivem suas histórias de dispersão, mitos, memórias da pátria e de alienação no país de acolhimento, suas memórias, histórias, narrativas, identidades de grupo, sonhos e elementos culturais são evidenciados por expressões da arte, música e até das artes marciais. No entanto, essas expressões culturais visam atender a um público local e são menos ligadas a um pertencimento de comunidade. Ao serem questionados se o fato de serem brasileiros ajudaria na Estônia as opiniões divergem. Enquanto alguns imigrantes apontam vantagens:

(No Brasil) as pessoas querem ouvir um sertanejo universitário, forró, uma coisa que abrange mais [...] Mas, a gente faz samba, samba-jazz. Eu canto coisas que já não são tão atraentes para os brasileiros. Mas assim, quando se fala de música brasileira, as pessoas vão lembrar de "Garota de Ipanema", as pessoas vão falar do Tom Jobim, as pessoas vão falar João Gilberto... Então, mal ou bem, eles colocaram a música brasileira no mapa da música no mundo. (entrevistado 2)

Tem um diferencial muito grande, né, é uma empresa controlada por um brasileiro que ensina em inglês, russo [sua esposa é russa] e português e que as pessoas procuram. Por quê? Porque é um brasileiro que está gerindo, que está controlando, está trabalhando. É alguém original, as pessoas que estão aqui já são [...] eu tenho todas as certificações exigidas aqui [...] eu coloquei a capoeira dentro do comitê Olímpico de esportes da Estônia. (entrevistado 4)

Eu acho que no Brasil você aprende ah, palavreado bem, você aprende a se "fuder", eu acho que essa habilidade é a maior qualidade do brasileiro e acho que ele traz, qualquer brasileiro traz isso, brasileiro trabalha muito bem, cara, muito bem. Mais flexível [...] precisa de dinheiro [...] aqui eles são, fala mais mole, eles já têm tudo pronto, cara, o país tá construído, tá tudo bonito, né, eles têm uma rede de proteção, ninguém é muito pobre aqui e nem muito rico, todo mundo vive uma vida boa [...] o brasileiro traz aqui e ele se destaca, eu acho, em qualquer emprego do "hot dog" ao gestor. (entrevistado 6)

Outros imigrantes já apontam desvantagens em ser brasileiro a depender da situação ou do negócio:

Atrapalha um pouco porque em relação a crédito, se eu quiser empréstimo, a taxa de juros é proibitiva mas até agora não foi um problema. (entrevistado 1)

A diferença (para) Estônia é bastante complexa. O brasileiro gosta muito de artes marciais, gosta muito de lutar, gosta muito de correr riscos no ponto de vista de aprendizado e os estonianos são mais cautelosos, levam mais tempo para tomar decisões e conhece menos as artes marciais que os brasileiros, os americanos. (entrevistado 7) 


\subsection{A formação da comunidade étnica e o empreendedorismo}

A dicotomia exposta por Bauman (2003), está expressa pelo conceito positivo de comunidade em contraponto com uma espécie de liberdade imprecisa, oriunda dos contextos pós-modernos, da exploração e do aprofundamento da estratificação da sociedade em classes econômicas, com a formação de guetos. Nesse sentido, a comunidade brasileira na Estônia, por estar em formação e por ser inserida num ambiente culturalmente tão diverso do brasileiro, traz algumas idiossincrasias, quer seja pela dificuldade linguística, ou pela quantidade ainda pequena de coétnicos, como apontado pelos dados do Itamaraty e da estimativa da atual pesquisa. A identificação de que se trata de uma comunidade étnica em formação foi destacada, além dos dados do Itamaraty (2016), por alguns depoimentos, sendo que estrangeiros e estonianos estão dentre os principais parceiros.

Meu Network é mais focado com fundadores estrangeiros que vem para a Estônia. (entrevistado 1)

Eu morava na Finlândia, eu tava treinando a equipe na Finlândia [...] vinha jogar beach-soccer nos fins de semana na Estônia no verão. [...] foi quando o cara que organiza o beach-soccer (estoniano), me falou que tinha um presidente de time querendo me conhecer. (entrevistado 2)

O número de pessoas que eu conheço tanto estonianos quanto brasileiros tem facilitado bastante meu empreendedorismo. (entrevistado 7)

Eu ensinei os estonianos a cultura brasileira, danças populares, ritmos e tal e eles me ensinaram as culturas estonianas, [...] criei um grupo baseado nisso. (entrevistado 8)

Além do entrevistado 7, outro depoimento evidenciou a existência de uma comunidade brasileira.

Ah sim, eu acho que a comunidade brasileira, [...] pelo menos conseguir me conectar aqui com ela pra perguntar e tentar tirar uma dúvida ou outra, ajuda. (entrevistado 6)

Já no tocante à definição de negócios étnicos, a qual está diretamente ligada aos fluxos migratórios e à comunidade brasileira, também se percebe claramente duas trajetórias comuns nos imigrantes brasileiros. Por um lado, um empreendedorismo motivado inicialmente pela "necessidade" de sobrevivência, quer seja dos músicos, jogadores de futebol e prestadores de serviços de TI. Já de outro estão inseridos os autônomos (Waldinger, Ward, Aldrich, 1985) ou até microempreendedores de tecnologia, nômades digitais ou e-cidadãos. Nota-se também a emergência de iniciativas das chamadas "empresas étnicas".

Nesse sentido, perguntou-se aos imigrantes, se já haviam pensado em serem empreendedores na Estônia, antes de saírem do Brasil, ao vislumbrarem oportunidades emergentes em diversos negócios relacionados a elementos culturais brasileiros, como alimentação, esporte ou cultura (música, artes marciais e dança). O planejamento incipiente dos negócios denota seu aspecto effectual (Sarasvathy, 2009, p. 16) de um empreendedorismo por necessidade, como explicitado a seguir. 
(Na verdade), a Estônia foi através de convite. E como eu morava na Finlândia, eu tava treinando a equipe na Finlândia e eu vinha jogar beach-soccer nos fins de semana na Estônia no verão. Foi quando a gente começou a ter os contatos, as pessoas começaram a me conhecer [...] estou atualmente há 11 anos, [...] O beachsoccer [...] na Estônia é muito forte, muito organizado e [...] aí eu trouxe mais dois brasileiros, três brasileiros e em quatro meses a gente subiu para liga em 90 anos de história. (entrevistado 2)

(No Brasil), eu diria que sempre tive um espírito empreendedor, mas eu não tinha formalmente uma empresa. [...] eu não trabalhava formalmente; eu trabalhava informalmente. Uma coisa que me influenciou muito foi na época do ensino médio, que eu participei do programa "Junior Achievement" [...] comecei a agir de uma outra maneira e ver de uma maneira diferente [...] Já na Estônia, eu consegui. Tipo, vim pra cá e eu era paga e eu percebi que eu podia viver disso (música). (entrevistado 3) Tenho (intenção de abrir sim). Talvez nos próximos... esperar um ano, dois pra ver, entender como funciona aqui melhor, pra ver se vale a pena a transferência. [...] preciso [...] empregar alguém no caso [...] o ramo tecnológico aqui pra mim eu vejo como o futuro lugar [...]. (entrevistado 6)

Mesmo no caso de negócios no ramo de tecnologia, há relatos de um empreendedorismo por oportunidade e alavancado pela facilidade de constituição da empresa ou menor burocracia:

Eu não conhecia a Estônia antes de sair do Brasil, eu inicialmente fui pra Irlanda treinar meu inglês, e aí eu usei o meu tempo para trabalhar nesse novo negócio e a Estônia me atraiu pela facilidade em empreender. No Brasil temos esse trauma por causa da burocracia [...] é um país onde tem menos impostos na Europa em si, com uma economia bastante libertária. No momento a empresa conta apenas os dois fundadores e nenhum funcionário ainda. Teremos em média uns 25-50 funcionários em 3 anos. (entrevistado 1)

$\mathrm{O}$ ato de empreender está totalmente vinculado à inserção dos indivíduos em redes sociais, como apontado pelas diversas trajetórias de empreendedores tanto da área cultural e esportiva, quanto os de tecnologia. As modalidades de negócios digitais, nômades digitais e até de cidadãos digitais (Tammpuu, Masso, 2018) emergem como possibilidades de auto-emprego de brasileiros, o que reforça ainda mais o conceito de Bauman (2003), da tensão relativa ao conflito entre os produtores e as fontes de sobrevivência. Nesse contexto, a facilidade de abertura e os incentivos de manutenção das empresas na Estônia são explicitadas a seguir:

A abertura da minha empresa levou de 15 a 20 minutos para preencher o formulário digital, fazer os ajustes no contrato social que é feito de forma eletrônica, no mesmo dia em 2 horas depois que eu fiz a aplicação já recebi o e-mail que a empresa já havia sido aberta. Já recebi o registro. No mesmo dia a noite eu já fiz a aplicação da conta empresarial e em menos de $12 \mathrm{~h}$ estava com minha conta aberta e no outro dia já fiz a aplicação da minha identidade no banco. [...] em 1 dia útil fiz a aplicação do VAT, recebi um e-mail oficial da Receita Federal pedindo clarificações em relação ao modelo de negócio, respondi e em poucas horas estava aprovado. (entrevistado 1)

A minha empresa [...] nossa filial na Bélgica: 3, 4 dias já estava pronta. Na Ucrânia [...] foi muito rápida. Aqui eu fiz tudo em casa, eu não saí de casa para nada, já tinha minhas licenças, já tinha tudo. [...] eu transformei a Estônia na matriz [...] vou lhe dizer porque: as condições oferecidas pela Estônia são bem melhores do que as que eu tinha em Portugal. (entrevistado 4) 
No entanto, os brasileiros destacam as diferenças culturais marcantes que podem impactar tanto em seu relacionamento pessoal quanto no ambiente de trabalho ou dos negócios:

(O idioma) me favoreceu [...] eu falo o Finlandês, falo, me comunico, entendo bem mas o idioma aqui é [...] o pessoal todo fala inglês aqui, isso facilita. (entrevistado 2)

O estoniano já é mais resguardado, ele não gosta muito de contato, está em um convívio com muitas pessoas, em grandes multidões [...] nós chegamos e vimos a comunidade russa [...] no primeiro ano eu comecei apenas com 15 integrantes. Na metade do mesmo ano, nós já estávamos em 150. Hoje, meus alunos giram em torno de 250 a 300 e estamos ainda em fase de crescimento... (entrevistado 4)

A língua estoniana também traz desafios de comunicação, gerando dificuldades que agravam ainda mais o fato deles serem mais fechados do que os brasileiros, conforme visto nos relatos a seguir:

Os estonianos são bem fechados e leva tempo pra fazer amizade com eles [...] A maioria dos jovens estonianos falam inglês, mas com os idosos que falam estoniano ou russo não tem comunicação. (entrevistado 1)

Ah língua é uma dificuldade bem grande. Você escuta o que seria mais fácil lidar só com o inglês aqui, mas a língua local é bem importante [...] trabalho numa startup, que é global, no escritório tem gente de trinta, quarenta nacionalidades diferentes, todos falam inglês. (entrevistado 5)

\section{Considerações finais}

O estudo preliminar das características da comunidade de brasileiros na Estônia nos traz a oportunidade de entender o imigrante brasileiro e suas considerações ao saírem de sua terra natal para novos destinos, mesmo que incertos e diferentes. Os imigrantes entrevistados têm muitos pontos em comum, como o fato de terem vivenciado experiências no exterior anteriores à sua chegada à Estônia e o fato de muitos deles já terem tido experiências empreendedoras anteriores (caso do empresário de capoeira, de artes marciais, dos músicos e dos profissionais de TI).

O imigrante brasileiro também traz novas interpretações para o dia a dia do país hospedeiro e por definição carrega uma ação transformadora. Assim, a sociedade local recebe os benefícios de uma emigração recente, de pessoas jovens economicamente ativas, com alto grau de formação escolar e técnica. Mesmo diante da ideia de Bauman (2003) de que na era atual, as comunidades são destruídas concomitantemente com a necessidade de pertencimento, demandada pela sociedade, nota-se a formação de uma pequena, embora ainda desarticulada, comunidade brasileira, cujas expressões culturais e negócios baseados na cultura brasileira visam mais a atender o público local.

Ademais, não deixam de existir barreiras culturais, geográficas e até burocráticas, as quais não restringem completamente a assimilação de brasileiros nesta região. Apesar das diferenças, a sociedade estoniana vem demonstrando interesse pela cultura brasileira. Programas musicais nas rádios da capital, participação de artistas, músicos, cantores, dançarinos, atletas e estudantes 
nos diversos eventos e festivais estonianos são exemplos da difusão da cultura brasileira. Por exemplo, produções brasileiras costumam participar do principal festival de cinema da Estônia e dos países bálticos, o Tallinn Black Nights. Em 2016, o longa "Reza a Lenda", de Homero Olivetto recebeu o Prêmio Especial do Júri na competição, e em 2018, foi realizada a primeira edição da Semana de Cinema Brasileiro em Tallinn (Embaixada do Brasil em Tallin, 2019). Foi criada também a "Escola de Samba Macieira de Ouro" que está em atividade há alguns anos e desfila seu carnaval nos meses de verão. A capoeira vem conquistando adeptos e já se pode observar eventos regulares de culinária brasileira em alguns espaços da cidade postados no grupo de Facebook de Brasileiros na Estônia.

Entretanto, se faz necessário colocar as interpretações em perspectiva. A Estônia continua sendo para os brasileiros uma possibilidade momentânea de uma experiência internacional e muitos pensam em retornar. Encontra-se no discurso corriqueiro de 'trabalhar, comer, viajar e guardar dinheiro', como destacam os entrevistados. Frases como 'eu não sabia onde ficava a Estônia e nunca tinha ouvido falar na cidade de Tallinn', também foi recorrentemente pronunciada.

Ainda que o Estado Estoniano pratique políticas de atração de mão-de-obra qualificada, o brasileiro que tenta se estabelecer no país está sujeito às regras de residência que incluem a necessidade de que um estrangeiro solicite uma autorização de residência e está sujeito à quota de imigração para estrangeiros, que não deve exceder $0,1 \%$ da população permanente da Estônia em um ano (Politsei, 2019).

Finalmente, para entender o que está acontecendo na migração Estoniana, deve-se estudar a cidadania e história local. A Estônia é marcada por sucessivas diásporas. Somente em 2017 que o saldo de migração líquida foi positivo. Em 2018, quase metade das pessoas que emigraram para a Estônia eram cidadãos Estonianos que retornaram, seguidos por cidadãos da Rússia, Ucrânia, Finlândia e Letônia. Parte do recente aumento na migração líquida resultou de melhorias nas regras para determinar residentes permanentes que permitiu calcular a imigração com mais precisão e revisar os números de imigração nos anos anteriores (Statistics Estonia, 2019). Entretanto, ainda não há números oficiais disponíveis para verificar a imigração de países terceiros, até então indeterminados, por partes dos serviços estatais da Estônia.

\section{Referências bibliográficas}

ALDRICH, Howard; REISS JR, Albert J. Continuities in the study of ecological succession: Changes in the race composition of neighborhoods and their businesses. American Journal of Sociology, v. 81, n. 4, p. 846-866, 1976.

ALMEIDA, Joanna; BIELLO, Katie B.; PEDRAZA, Francisco; WINTNER, Suzanne; VIRUELL-FUENTES, Edna. The association between anti-immigrant policies and perceived discrimination among Latinos in the US: A multilevel analysis. SSMpopulation health, v. 2, p. 897-903, 2016. 
AMARAL, Ana Paula Martins; COSTA, Luiz Rosado; ALLGAYER, Cristiane Batista Arrua. O brasileiro como estrangeiro: a política migratória brasileira para emigrantes. Cadernos de Direito, v. 17, n. 33, p. 257-285, 2017.

AROLES, Jeremy; GRANTER, Edward; DE VAUJANY, François-Xavier. 'Becoming mainstream': the professionalisation and corporatisation of digital nomadism. New Technology, Work and Employment, v. 35, n. 1, p. 114-129, 2020.

ATKINSON, Rowland; FLINT, John. Accessing hidden and hard-to-reach populations: Snowball research strategies. Social research update, v. 33, n. 1, p. 1-4, 2001.

AYER, Flavia. Mudança de 21,8 mil brasileiros para o exterior até julho supera quase toda a saída em 2018. O Estado de Minas, 10.08.2019. Disponível em: < https:// www.em.com.br/app/noticia/politica/2019/08/10/interna_politica,1076303/ mudanca-de-21-8-mil-brasileiros-para-o-exterior-ate-julho-supera-quase.shtml>. Acesso em: 15.10.2019.

BALTAR, Fabiola; ICART, Ignasi Brunet. Entrepreneurial gain, cultural similarity and transnational entrepreneurship. Global Networks, v. 13, n. 2, p. 200-220, 2013.

BARDIN, Laurence. Análise de conteúdo. Lisboa/Portugal: Edições 70, 2006.

BARRETT, Giles A.; JONES, Trevor P.; MCEVOY, David. Ethnic minority business: theoretical discourse in Britain and North America. Urban studies, v. 33, n. 4-5, p. 783-809, 1996.

BAUMAN, Zygmunt. Comunidade: a busca por segurança no mundo atual. Rio de Janeiro: Zahar, 2003.

BOUDREAUX, Christopher J. Ethnic diversity and small business venturing. Small Business Economics, v. 54, n. 1, p. 25-41, 2020.

BRASILEIROS NA ESTÔNIA. Website. 2019. Disponível em: < http://www.brasileiros. ee/>. Acesso em: 15.10.2019.

CASTRO LIMA, Álvaro Eduardo de; CASTRO, Alanni de Lacerda Barbosa de. Brasileiros nos Estados Unidos - Meio Século (Re)fazendo a América (1960-2010). REMHU, Revista Interdisciplinar da Mobilidade Humana, v. 26, n. 52, p. 273-275, 2018.

CHAGANTI, Radba; GREENE, Patricia G. Who are ethnic entrepreneurs? A study of entrepreneursapos; ethnic involvement and business characteristics. Journal of small business management, v. 40, n. 2, p. 126-143, 2002.

CHAND, Masud; TUNG, Rosalie L. Skilled immigration to fill talent gaps: A comparison of the immigration policies of the United States, Canada, and Australia. Journal of International Business Policy, v. 2, n. 4, p. 333-355, 2019.

CRUZ, Eduardo Picanço; JESUS, Daniele Maria Oliveira de; FALCÃO, Roberto Pessoa de Queiroz; LOPES, Luiz Antonio Coelho; PETRI, Fernando Celso; MELO, Igor Marques de; JUNIOR, Ricardo Moura de Souza. Relatório de Pesquisa sobre os brasileiros na Austrália. Niterói: Departamento de Empreendedorismo e Gestão da UFF, 2016.

CRUZ, Eduardo Picanço; FALCÃO, Roberto Pessoa de Queiroz; MANCEBO, Rafael Cuba; CASTRO, Andrea Ribeiro Carvalho de. Trajetórias do empreendedorismo imigrante e estratégias de mercado a partir das experiências de brasileiros no exterior. Cadernos de Gestão e Empreendedorismo, v. 5, n. 2, p. 37-54, 2017. 
CRUZ, Eduardo Picanço; FALCÃO, Roberto Pessoa de Queiroz; BARRETO, Cesar Ramos. Estudo exploratório do empreendedorismo imigrante brasileiro em Pompano beach e Orlando-EUA. Gestão \& Planejamento-G\&P, v. 18, 2017.

CRUZ, Eduardo Picanço; FALCÃO, Roberto Pessoa de Queiroz; MANCEBO, Rafael Cuba. Market orientation and strategic decisions on immigrant and ethnic small firms. Journal of International Entrepreneurship, v. 18, p. 1-29, 2019.

CRUZ, Eduardo Picanço; FALCÃO, Roberto Pessoa de Queiroz; PAULA, Fábio de Oliveira. Analysis of prescribing variables of entrepreneurial intention of Brazilian immigrants in Portugal. Revista de Administração Contemporânea, v. 24, n. 4, p. 349-368, 2020.

EMBAIXADA BRASILEIRA EM TALLINN. Comunidade brasileira na Estônia. 2019. Disponível em: <http://talin.itamaraty.gov.br/pt-br/comunidade_brasileira_na_ Estônia.xml/>. Acesso em: 15.11.2019.

E-RESIDENT. Total number of e-residents. 2019. Disponível em: <https://e-resident. gov.ee/dashboard/>. Acesso em: 10.01.2020.

EVANS, Yara; WILLS, Jane; DATTA, Kavita; HERBERT, Joanna; MCILWAINE, Cathy; MAY, Jon; ARAÚJO, Father José Osvaldo de; FRANÇA, Ana Carla; FRANÇA, Ana Paula. Brazilians in London: a report for the Strangers into Citizens Campaign. London: Department of Geography, Queen Mary, University of London, 2007.

FALCÃO, Roberto Pessoa de Queiroz; CRUZ, Eduardo Picanço; AMARAL, Sabrina Sampaio. Identificando negócios imigrantes e fluxo de informações em uma comunidade virtual de brasileiros em Sidney. Revista Livre de Sustentabilidade e Empreendedorismo, v. 3, n. 1, p. 125-147, 2018.

GOLD, Steven J.; LIGHT, Ivan. Ethnic economies and social policy. Research in social movements, conflicts and change, v. 22, Emerald Group Publishing Limited, p. 165191, 2000.

GOLLIN, Douglas. Nobody's business but my own: Self-employment and small enterprise in economic development. Journal of Monetary Economics, v. 55, n. 2, p. 219-233, 2008.

GUARNIZO, Luis Eduardo; PORTES, Alejandro; HALLER, William. Assimilation and transnationalism: determinants of transnational political action among contemporary migrants. American journal of sociology, v. 108, n. 6, p. 1211-1248, 2003.

HÜSING, Tobias; HÜSING, Tobias; KORTE, Werner B.; FONSTAD, Nils; LANVIN, Bruno; CATTANEO, Gabriella; KOLDING, Marianne; LIFONTI, Rosanna; van WELSUM, Desirée. E-leadership: E-skills for Competitiveness and InnovationVision, Roadmap and Foresight Scenarios. Bonn: European Commission, 2013.

IBRUS, Indrek. Estonian Human Development Report 2016/2017. Estonian digital culture policies in international space: Development and barriers. 2017. Disponível em: <https://2017.inimareng.ee/en/estonias-cultural-changes-in-an-open-world/est onian-digital-culture-policies-in-international-space/>. Acesso em: 10.01.2020.

ITAMARATY. Brasileiros pelo mundo: estimativas populacionais. 2016. Disponível em: <http://www.brasileirosnomundo.itamaraty.gov.br/a-comunidade/estimativas populacionais-dascomunidades $>$. Acessado em: 04.03.2016. 
JAKITAS, Renato. Estônia é novo destino de profissionais brasileiros de TI. O Estado de S. Paulo, 02.12.2019. Disponível em: < https://economia.estadao.com.br/noticias/ geral,Estônia-e-novo-destino-de-profissionais-brasileiros-de-ti,70003109790> .

JARRAHI, Mohammad Hossein; PHILIPS, Gabriela; SUTHERLAND, Will; SAWYER, Steve; ERICKSON, Ingrid. Personalization of knowledge, personal knowledge ecology, and digital nomadism. Journal of the Association for Information Science and Technology, v. 70, n. 4, p. 313-324, 2019.

JONES, Trevor; RAM, Monder. Re-embedding the ethnic business agenda. Work, Employment and Society, v. 21, n. 3, p. 439-457, 2007.

JÜRISSON, Sander. Kuldsele Kaananimaale: esimestest eesti väljarändajatest Brasiilias. Mäetagused. Hüperajakiri, n. 50, p. 91-112, 2012.

KATTEL, Rainer; MERGEL, Ines. Estonia's digital transformation: Mission mystique and the hiding hand. UCL Institute for Innovation and Public Purpose working Paper Series (IIPP WP 2018-09), 2018.

KAUSHIK, Vibha; DROLET, Julie. Settlement and integration needs of skilled immigrants in Canada. Social Sciences, v. 7, n. 5, p. 76, 2018.

KLOOSTERMAN, Robert; RATH, Jan. Immigrant entrepreneurs in advanced economies: mixed embeddedness further explored. Journal of ethnic and migration studies, v. 27, n. 2, p. 189-201, 2001.

LIGHT, Ivan. Ethnic enterprise in America. Los Angeles: University of California Press, 1972.

MAHER, Garret; CAWLEY, Mary. Short-term labour migration: Brazilian migrants in Ireland. Population, Space and Place, v. 22, n. 1, p. 23-35, 2016.

MARGETTS, Helen; NAUMANN, Andre. Government as a platform: What can Estonia show the world. Research paper, University of Oxford, 2017.

MARGOLIS, Maxine L. Goodbye, Brazil: emigrantes brasileiros no mundo. São Paulo: Editora Contexto, 2013.

METS, Tõnis. Entrepreneurship in Estonia: Combination of political and entrepreneurial agenda. In: SAUKA, Arnis; CHEPURENKO, Alexander (eds.). Entrepreneurship in Transition Economies. Cham: Springer, 2017, p. 115-133.

METS, Tõnis. Is Estonia becoming a better home for 'born globals'?. In: SMALLBONE, David; VIRTANEN, Markku; SAUKA, Arnis (eds.). Entrepreneurship, innovation and regional development. United Kingdom: Edward Elgar Publishing, 2016.

MORETTI, Enrico. The new geography of jobs. Boston: Houghton Mifflin Harcourt, 2012. PAJUMETS, Marion. Pathways to citizenship for third-country nationals in the EU Member States (Country report Estonia). EMN Estonia. 2019. Disponivel em: $<$ https:/www.emn.ee/en/publication/kolmandate-riikide-kodanike-voimalusedsaada-eli-liikmesriikide-kodakondsus/>. Acesso em: 10.01.2020.

PEDASTE, Margus; KORI, Külli; TÕNISSON, Eno; PALTS, Tauno; ALTIN, Heilo; RANTSUS, Ramos. What Happens to IT Education? The Case in Estonia with Some Recommendations for International Discussion. International Journal of Information and Education Technology, v. 7, n. 3, p. 204, 2017. 
PETRAITE, Monika; DLUGOBORSKYTE, Vytaute. Comparative evolutionary study on transitions of national innovation systems in the Baltic Region. International Journal of Economics and Business Research, v. 14, n. 3-4, p. 332-355, 2017.

POLI, Ana Carolina. 5 motivos para não morar na Estônia. Blog Brasileiras pelo mundo. 2018. Disponível em: < https://www.brasileiraspelomundo.com/motivos-para-naomorar-na-Estônia-081078545>. Acesso em: 10.01.2020.

POLITSEI. Police and Border Guard Board. 2019. Disponível em: <https://www2. politsei.ee/en/teenused/residence-permit/>. Acesso em: 10.01.2020.

PORTES, Alejandro; BACH, Robert L. Latin journey: Cuban and Mexican immigrants in the United States. Berkeley: Univ of California Press, 1985.

PORTES, Alejandro; ZHOU, Min. Gaining the upper hand: Economic mobility among immigrant and domestic minorities. Ethnic and racial studies, v. 15, n. 4, p. 491-522, 1992.

RAIJMAN, Rebeca; TIENDA, Marta. Ethnic foundations of economic transactions: Mexican and Korean immigrant entrepreneurs in Chicago. Ethnic \& Racial Studies, v. 26, n. 5, p. 783-801, 2003.

REDFIELD, Robert. The little community and peasant society and culture. Chicago: University of Chicago Press, 1989.

RIBEIRO, Carlos Henrique de Vasconcellos; DIMEO, Paul. The experience of migration for Brazilian football players. Sport in Society, v. 12, n. 6, p. 725-736, 2009.

ROCHA, Angela da; ESTEVES, Felipe; MELLO, Renato Cotta de; SILVA, Jorge Ferreira da. Diasporic and transnational internationalization: the case of Brazilian martial arts. BAR-Brazilian Administration Review, v. 12, n. 4, p. 403-420, 2015.

ROSENBERG, Rachel. Uma comunidade centrada na pessoa. In: ROGERS, Carl; ROSENBERG, Rachel. A pessoa como centro. São Paulo: EPU, 1977, p. 103-132.

SARASVATHY, Saras D. Effectuation: Elements of entrepreneurial expertise. Northampton, MA: Edward Elgar Publishing, 2009.

SCHLAGWEIN, Daniel. "Escaping the Rat Race": Justifications in Digital Nomadism. Research-in-Progress Papers 31. 2018. Disponível em: $<$ https://aisel.aisnet.org/ecis2018_rip/31>.

SCHLUETER, Elmar; MASSO, Anu; DAVIDOV, Eldad. What factors explain antiMuslim prejudice? An assessment of the effects of Muslim population size, institutional characteristics and immigration-related media claims. Journal of Ethnic and Migration Studies, v. 46, n. 3, p. 1-16, 2018.

SCHULER, Flavia da Maria Gomes; SOUZA BRITO, Cristina Maria de. Migration for Love? A Study of Brazilian Women Married to Swiss Men. Psychology Research, v. 4, n. 1, p. 48, 2014.

SCOTT, Allen J. A world in emergence: cities and regions in the 21st century. United Kingdom: Edward Elgar Publishing, 2012.

SHUVAL, Judith T. Diaspora migration: Definitional ambiguities and a theoretical paradigm. International migration, v. 38, n. 5, p. 41-56, 2000. 
SOCZEK, Daniel. Comunidade, utopia e realidade: uma reflexão a partir do pensamento de Zygmunt Bauman. Revista de Sociologia e Política, n. 23, p. 175-177, 2004.

STATISTICS ESTÔNIA. Statistical Council. 2019. Disponível em: <https://www.stat.ee/ en >. Acesso em: 10.01.2020.

TAMMPUU, Piia; MASSO, Anu. 'Welcome to the virtual state': Estonian e-residency and the digitalised state as a commodity. European Journal of Cultural Studies, v. 21, n. 5, p. 543-560, 2018.

WADHWA, Vivek; SAXENIAN, AnnaLee; RISSING, Ben A.; GEREFFI, Gary. America's new immigrant entrepreneurs. Berkeley: Kauffman Foundation report, 2007.

WALDINGER, Roger; WARD, Robin; ALDRICH, Howard. Ethnic business and occupational mobility in advanced societies. Sociology, v. 19, n. 4, p. 586-597, 1985.

WANG, Blair; SCHLAGWEIN, Daniel; CECEZ-KECMANOVIC, Dubravka; CAHALANE, Michael C. Digital work and high-tech wanderers: Three theoretical framings and a research agenda for digital nomadism. ACIS 2018 Proceedings, 55. Disponível em: $<$ https://aisel.aisnet.org/acis2018/55>. 